\title{
Saudi Arabia Alternative Energy Research Learning from the Experience of China
}

\author{
Baslom Mohammed Majdy $\mathrm{M}^{1, \text { a }}$, Ying $\mathrm{Li}^{2, \mathrm{~b}}$ \\ ${ }^{12}$ School of business, East China University of Science and Technology, Shanghai, China \\ ab kzsnyhp@163.com
}

\begin{abstract}
Keywords: Alternative energy; Saudi Arabia; Energy policy
Abstract. Economic growth cannot be separated from the energy which is an important material basis for economic development. Since the 20th century, with global population growth and economic expansion of the scale, Economic development has led to large amounts of energy consumption, increasingly acute contradictions between the limitation of traditional energy resources and the sustainability of economic growth. At the same time the environmental pollution caused by the use of traditional energy, climate warming, so that there is an urgent search for alternative energy. In this context, the development and utilization of alternative energy are gradually accepted by many governments. Saudi Arabia government has paid great attention to the development of alternative energy. But alternative energy development and utilization of Saudi Arabia are in the initial stage; however, alternative energy in China has a rapid development and got lot achievements. The achievements, goals, and developing problems in the development of China's alternative energy system are analyzed in detail which has important significance for Saudi Alternative energy system's construction. The Saudi national conditions are analyzed including the situations of alternative energy in Saudi Arabia and the current alternative energy strategy. At last, learning from China, we present and summarize Saudi Arabia alternative energy system policy recommendations.
\end{abstract}

\section{Introduction}

Since the 20th century, with the global population growth and economic development, economic development has led to a lot of energy consumption, followed by the contradiction between the limitation of traditional energy resource and the sustainability of economic growth. At the same time, the use of traditional energy caused serious environmental pollution and greenhouse effect. In this context, more and more governments consider using alternative energy. In a general sense, alternative energy as it is currently conceived is that which is produced or recovered without the undesirable consequences inherent in fossil fuel use, particularly high carbon dioxide emissions, an important factor in global warming.

China Investment Corporation, a US\$300 billion-asset-holding state wealth fund, is investing heavily in Chinese clean-energy companies and foreign operators with projects in China. Similarly, the China Energy Conservation Investment Corporation, a state holding company, invests heavily in energy conservation, pollution control and alternative energy private sector projects.

Compared with China, in 2010, Saudi Arabia was the world's largest producer and exporter of petroleum liquids and the world's second largest crude oil exporter, behind Russia. Oil export revenues account for 80 to 90 per cent of total Saudi revenues and over 40 per cent of the country's gross domestic product (GDP). Saudi Arabia is also home to around one-fifth of proven, conventional world oil reserves, including the 1,260-square mile Chuwar field (the world's largest oil field, with estimated remaining reserves of 70 billion barrels), which alone has more proven oil reserves than all but six other countries.

Saudi Arabia needs a long time to transform their minds. The development of new energy needs to formulate relevant policy, and also needs funding support. Luckily, Saudi Arabia could learn from China, in which the alternative energy has been developed for a long time, and has obtained good achievements. Therefore, this article will focus on comparison of the development of new energy policies and direction of the two countries. 


\section{Utilization of alternative energy development}

(1) The global alternative energy development

In 2013, in the global energy consumption, fossil energy, nuclear energy, alternative energy accounted for $86.7 \%, 4.4 \%$ and $86.7 \%$ respectively. Compared with 2004 , fossil fuels and nuclear energy consumption fell, rising, the proportion of alternative energy consumption increased from $6.8 \%$ to $8.9 \%$. Shown in the following table:

Table.1. Global energy consumption

\begin{tabular}{|l|l|l|l|l|l|l|l|l|}
\hline & Oil & Natural gas & Coal & $\begin{array}{l}\text { Nuclear } \\
\text { energy }\end{array}$ & $\begin{array}{l}\text { Hydroelectric } \\
\text { power }\end{array}$ & Wind & $\begin{array}{l}\text { The solar } \\
\text { energy }\end{array}$ & $\begin{array}{l}\text { Biomass } \\
\text { energy }\end{array}$ \\
\hline 2004 & $37.2 \%$ & $23.3 \%$ & $26.7 \%$ & $6.0 \%$ & $6.1 \%$ & $0.2 \%$ & $0.006 \%$ & $0.5 \%$ \\
\hline 2013 & $32.7 \%$ & $23.6 \%$ & $30.4 \%$ & $4.4 \%$ & $6.7 \%$ & $1.1 \%$ & $0.2 \%$ & $0.9 \%$ \\
\hline
\end{tabular}

In alternative energy, hydropower, especially large hydropower projects, as a traditional and alternative energy projects, still occupied the main position in alternative energy consumption overall. In 2013, hydroelectric energy accounted for $75 \%$ of overall consumption of alternative energy. But the growth of hydropower is significantly lower than the water wind, solar, biomass and geothermal, etc. As a new alternative energy, from 2004 to 2013, the fastest growing is wind energy and solar energy. In alternative energy accounted for, the wind power is from $0.03 \%$ to $0.1 \%$, the solar energy is from $0.0008 \%$ to $0.02 \%$. Biomass energy, geothermal and other accounted for the total alternative energy from $0.08 \%$ to $0.1 \%$. However, hydropower reduced from $0.9 \%$ to $0.8 \%$.

alternative energy production in the field of electric power is the most representative. In 2013, the global alternative energy power total installed capacity of 1560 gigawatts (GW), accounted for 23\% of global electricity a total installed capacity, up 8\% from 2012. Hydroelectric power alternative energy electricity installed capacity of 560 gigawatts (GW).

According to the international association of geothermal (IGA) data, cumulative installed geothermal power generation capacity of $1.1709 \mathrm{GW}$ in 2013, up 3.1\% from 2012. Among them, the cumulative installed geothermal power generation capacity of $0.3442 \mathrm{GW}$, accounting for $29.4 \%$ of the total; Followed by the Philippines, cumulative installed geothermal power generation capacity of $0.1868 \mathrm{GW}$ accounted for $16.0 \%$ of the world; The next $11.4 \%$ of Indonesia $(0.1339 \mathrm{GW})$ and $7.3 \%$ (0.0855 GW) of New Zealand.

Cumulative installed solar power capacity is $13.9637 \mathrm{GW}$ in 2013, up 36.8\% from 2012. Among them, the German is the highest in the world by cumulative installed solar power capacity of 3.5948 GW, $25.7 \%$ of the total. Followed by China, and the accumulative installed solar power capacity is $1.83 \mathrm{GW}$ accounted for $13.1 \%$ of the world. Next is Italy's $12.6 \%(1.76 \mathrm{GW})$ and $9.8 \%(1.36 \mathrm{GW})$ of Japan.

The accumulative installed wind power capacity is 31.9907 GW in 2013, up 37.5\% from 2012. Among them, China is the highest in the world by the accumulative installed wind power capacity of 9.1460 GW, $28.6 \%$ of the total. Followed by the United States, the cumulative installed solar power capacity is6.1292 GW accounted for $19.2 \%$ of the world. The next is $10.7 \%$ of German (3.4316 GW) and $7.2 \%(2.2898 \mathrm{GW})$ of Spain.

(2) The development of alternative energy of China

Achievements: During the period of "11th five-year plan", alternative energy of China get leap development. By the end of 2010, China's alternative energy totaled 300 million tons of standard coal, accounting for the proportion of the total energy consumption 9\%. From the segmentation perspective, the wind power installed capacity in the period of "11th five-year plan" is 40 times compared to the period of "10th five-year plan".

Chinese alternative energy reserves and goals: "Twelfth five-year plan" alternative energy development goals in the total target is proposed: Enlarging the scale of the application of alternative energy, promoting alternative energy and conventional energy system integration, raising the 
proportion of alternative energy in energy consumption; Comprehensively promoting alternative energy technology innovation ability, mastering the core technology of alternative energy, building perfect and competitive system of alternative energy industry.

\begin{tabular}{|c|c|c|c|c|c|c|}
\hline \multicolumn{7}{|c|}{ Chinese R enewable Energy R esource } \\
\hline \multirow{5}{*}{ Hydroenergy } & \multicolumn{2}{|c|}{ Theory P o ten tia lity } & \multicolumn{2}{|c|}{ TechnicalE xp lo itation } & \multicolumn{2}{|c|}{ Econom ic Exploitation } \\
\hline & Ins talled & Annual & Installed & Annual & Ins talled & A nnual \\
\hline & C apac ity & 0 utput & C apac ity & 0 utput & C apac ity & 0 utput \\
\hline & $\begin{array}{c}\text { Ten } \\
\text { thousand } \\
\text { KW }\end{array}$ & $\begin{array}{c}\text { Hundred } \\
\text { m illion } \\
\text { KW H }\end{array}$ & $\begin{array}{c}\text { Ten } \\
\text { thousand } \\
\text { KW }\end{array}$ & $\begin{array}{c}\text { Hundred } \\
\text { m illion K W H }\end{array}$ & $\begin{array}{c}\text { Ten } \\
\text { thousand } \\
\text { KW }\end{array}$ & $\begin{array}{c}\text { Hundred } \\
\text { m illion KW H }\end{array}$ \\
\hline & 69,440 & 60,829 & 54,164 & 24,740 & 40,180 & 17,534 \\
\hline \multirow{7}{*}{$\begin{array}{c}\text { B iom ass energy } \\
\text { (hundred m illion tons) }\end{array}$} & \multirow{2}{*}{\multicolumn{2}{|c|}{ Item }} & \multirow{2}{*}{ Resource } & \multirow{2}{*}{ A va ilable } & \multicolumn{2}{|c|}{ U sable } \\
\hline & & & & & Unit & Standard C oal \\
\hline & \multicolumn{2}{|c|}{ C rop S traw } & 6.81 & 5.46 & 1.38 & 0.69 \\
\hline & \multicolumn{2}{|c|}{ Forest Residues } & 1.25 & 1.25 & 1.25 & 0.63 \\
\hline & \multicolumn{2}{|c|}{ Lives tocks Excrem ents } & 2.39 & 2.39 & 2.39 & 1.07 \\
\hline & \multicolumn{2}{|c|}{$\begin{array}{l}\text { Indus trialo rganic w aste } \\
\text { (M 3) }\end{array}$} & 500 & 500 & 500 & 0.39 \\
\hline & \multicolumn{2}{|c|}{ U rban 0 rgan ic W as te } & 1.5 & 1.5 & 0.15 & 0.02 \\
\hline \multirow[b]{2}{*}{ SolarE nergy } & \multicolumn{2}{|c|}{ A nnualR ad ia tion } & \multicolumn{2}{|c|}{ A nnual absorb energy } & \multicolumn{2}{|c|}{ A nnualu sable } \\
\hline & \multicolumn{2}{|c|}{$5 \times 10^{\wedge} 22 \mathrm{~J}$} & \multicolumn{2}{|c|}{$\begin{array}{l}1.7 \text { trillion tons of } \\
\text { s tandard coal }\end{array}$} & \multicolumn{2}{|c|}{2.2 B illion $\mathrm{KW}$} \\
\hline \multirow{2}{*}{$\begin{array}{l}\text { W ind pow er (hundred } \\
\text { m illion kilow atts) }\end{array}$} & \multicolumn{2}{|c|}{0 nshore w ind energy } & \multicolumn{2}{|c|}{0 ffshore w ind pow er } & \multicolumn{2}{|c|}{ Total } \\
\hline & \multicolumn{2}{|c|}{25.6} & \multicolumn{2}{|c|}{1.9} & \multicolumn{2}{|c|}{27.5} \\
\hline \multirow{2}{*}{$\begin{array}{c}0 \text { cean energy (hundred } \\
\text { m illion kilow atts) }\end{array}$} & Total & $\begin{array}{c}\text { Tidal } \\
\text { P ow er }\end{array}$ & $\begin{array}{c}\text { W ave } \\
\text { Energy }\end{array}$ & $\begin{array}{c}\text { Tidal } \\
\text { Current }\end{array}$ & $\begin{array}{l}\text { O sm otic } \\
\text { Energy }\end{array}$ & $\begin{array}{c}\text { Tem perature } \\
\text { Energy }\end{array}$ \\
\hline & 14.95 & 0.22 & 0.13 & 0.14 & 1.25 & 13.21 \\
\hline
\end{tabular}

Figure.1. China's alternative energy resource

Table.2. Main indicators of alternative energy development and utilization in "Twelfth five-year plan"

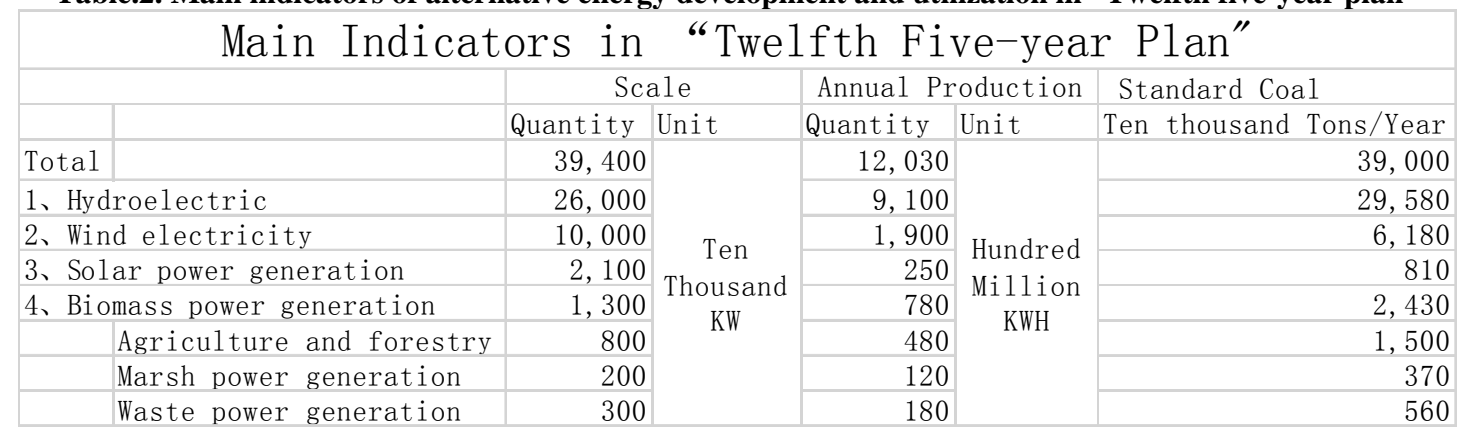

\section{Saudi Arabia alternative energy stats}

\section{(1) Saudi Arabia Wind energy}

In the early last century, the Saudi government studied more than 20 cities with wind energy. The advantages of wind power is mainly that it is clean sources of energy and it can be renewable. Wind power facilities are becoming more and more progress. Wind power cost is lower than the generator in appropriate locations with reducing costs by scale effect. Wind power facilities are not three-dimensional facilities which can protect land and ecology. The disadvantage of wind power generation is that it may interfere with birds. Wind power on wind speed has certain requirements. In general, if the annual average wind speed more than $3.5 \mathrm{~m} / \mathrm{s}$ on the local 10 meters height, it can carry out feasibility studies. But from the perspective of economic and reasonable, the wind speed is greater 
than $4 \mathrm{~m} / \mathrm{s}$ is suitable for power generation, and the greater the wind, the more economic benefits. At the same time, the wind can be divided into onshore wind power and offshore wind power.

Saudi government collected the wind data and measured the wind power costs including investment costs, operating costs, maintenance costs and the cost of capital. Investment costs include: wind energy conversion costs, additional equipment cost, cost of the grid connection, and planning, industry access costs. Operation and maintenance costs include the maintenance cost, insurance cost, monitoring cost and management cost; Capital costs include the cost of interest and to repay the loan. By monitoring, whether by $2500 \mathrm{KW}, 1300 \mathrm{KW}$ or $600 \mathrm{KW}$ wind motor, Yanbo has the lowest cost of power generation, and then the Qaisumah. According to relevant information, the annual maximum wind speed $25.65 \mathrm{~m} / \mathrm{s}$ above the ground plane of 10 meters in Yanbo, meeting the power requirements of wind speed of more than $50 \%$ of all the year round. Qaisumah which is located in the inland, meet the requirements of the power of wind speed for the $45+5 \%$. However, there are no data information show that the Saudi Arabia has wind power.

(2) Saudi Arabia solar energy

Saudi territory is mainly in between 21 to 26 degrees north latitude, land area of 225 square kilometers, sufficient sunlight. Saudi Arabia is one of the best global pv conditions, and the average solar irradiation is twice as large as Europe. In May 2012, Saudi King Abdullah Atomic Energy and alternative energy City K.A.CARE released the announcement on the fourth Saudi solar summit that two phases construction totaled $6.65 \mathrm{GW}$ of alternative energy projects will be set up. By 2032, complete the $41 \mathrm{GW}$ solar power, nuclear power installed 17 gigawatts (GW), wind power, biomass and geothermal total 13 gigawatts $(\mathrm{GW})$. The target of photovoltaic solar power installation, photovoltaic installations for $16 \mathrm{GW}$, concentrated solar power (CSP) installed for 25 gigawatts (GW). Phases 1: Solicit the construction project of the 2850 MW capacity, including 1100 megawatts of solar photovoltaic, 900 megawatts of concentrated solar power projects, 650 megawatts of wind power projects and other projects 200 megawatts. The project will officially started in 2014, and grid in 2015. Phases 2: in 2014-2015 period, the construction of solar photovoltaic, solar, wind and other projects capacity respectively $1300 \mathrm{MW}, 1200 \mathrm{mw}, 1300 \mathrm{mw}$ and $1200 \mathrm{MW}$. K.A.CARE is also working with IBM in Al Khafjim to build a world's largest, solar-powered desalination plant. The factory will use advanced photovoltaic technology for factory supply electric power. This solar electricity can be closely combined with seawater desalination. The energy intensive mode is needed in Saudi desalination.

However, Saudi postponed its 16 GW target from 2032 to 2040. The target is equivalent to an annual increase of installed capacity of $640 \mathrm{mw}$ in the next 25 years. The Saudi government has claimed its alternative energy development plan in recent years. However, by the end of 2011, Saudi Arabia's solar capacity is less than $40 \mathrm{MW}$.

\section{Saudi Arabia's alternative energy strategy}

K.A.CARE released the plan that in 2032, Saudi Arabia is expected to start more than $\$ 60$ billion in total solar power project procurement, as well as another 13 gigawatts of wind energy, geothermal and garbage farms. (Now it postponed to 2040). The plan show that K.A.CARE takes a comprehensive way and tries to achieve multiple goals. At the same time, the paper also talked about the architecture, time limit, technical target, eligibility criteria and assessment.

According to K.A.CARE, the alternative energy projects will be three programs: boot stage, the first round and second round. Boot stage is expected to achieve $500 \mathrm{MW}$ to $500 \mathrm{MW}$, including eight projects. The first round is expected to reach $3000 \mathrm{MW}$. The second round is of $3000-4000 \mathrm{MW}$. K.A.CARE forecasted 12 to 18 months between each round and each round will need eight to ten months. K.A.CARE think that the target of $54 \mathrm{GW}$ in 20 years are unrealistic, but the whole strategy of technology conditions shows it is achievable.

From the perspective of photovoltaic power generation, it will have continuously every year about 800-1000 megawatts of installed capacity after boot stage. This is good for the industry itself 
because of the providing a means of sustainable development. In terms of concentrated sunlight and wind power, it also can have roughly the same size of growth. It will be gradually from zero to a stable trend from the boot stage, the first round to the second round.

This plan put forward a series of restrictions and standards for the alternative energy strategy in view of the fact that the world market is facing the uncertainty and supply ongoing integration. The plan pointed out that a bidder can only bid for $30 \%$ of the capacity for any kind of technology in each round. K.A.CARE said that the move was to introduce companies to participate in as much as possible, especially in the early part of the procurement project.

The plan also proposes a stage before bidding in the financial capacity and experience requirements. K.A.CARE seeking an investment level standard based on $\$ 100000$ per megawatt in the financial capacity. At the same time, on the experience, the bidder's be asked that an experience are matched the vision plan experience level.

\section{Saudi Arabia alternative energy system policy recommendations}

As a long-term strategic task, development of alternative energy must be persistent. According to the needs of market development as well as the establishment of internationally competitive industry system, Saudi Arabia should strengthen legislation, strengthen the basic research, establish perfect policy and institutional frameworks, and improve and maintain contains overall service system of talent training. To encourage the development of alternative energy, a long-term, positive and steady support should be given to the alternative energy systems.

Based on the experience of China and some other countries, Saudi Arabia should modify, supplement and improve the alternative energy policy and practices, and the same time, research and develop new and alternative energy policy and measures. For this purpose, combined with the analysis of the above, this paper offers the following suggestions.

Improve the alternative energy rules and regulations on the basis of national law. According to China's development in the field of alternative energy, we can clearly know that strengthening the legislation is one of the successful experience of the development of alternative energy. Improving the alternative energy rules and regulations are the very important means in practice.Establish market policies. After the overall planning and establishment of corresponding supporting measures, the government should have the feasible measures to clearly stimulate the development of alternative energy market. As is known to all, at the early stages of development, the alternative energy system is faced the question of high cost, the lack of market competitiveness and so on. In order to overcome these shortcomings, strong planning and deployment and definite major feasible implementing scheme should be enacted. In combination with environmental policy, supply policy and demand policy. Support R\&D innovation, training technical personnel. Improve the alternative energy management system. International exchanges and cooperation: Through developing alternative energy international cooperation, Saudi Arabia mainly gains three aspects of the benefits: Firstly, a lot of financial support, it guarantee the development and utilization of alternative energy in a timely and effective manner. Secondly, through the introduction of advanced technology, it accelerates the technology research and development process. Thirdly, Absorbing foreign experience, perfect management and development policies, it accelerate the system reform and the cultivation of talents.

\section{References}

[1] Zou Zhiqiang. Saudi Arabia and global economic governance in the perspective of petrodollars [J]. The world economic and political meeting. 2013, 15(5): 77-82.

[2] Porter M E, Van der Linde C. Toward a new conception of the environment-competitiveness relationship[J]. The journal of economic perspectives. 1995: 97-118.

[3] Byosiere P, Luethge D J, Vas A, et al. Diffusion of organisational innovation: knowledge transfer through social networks[J]. International Journal of Technology Management. 2010, 49(4): 401-420. 
[4] Inkpen A C, Tsang E W K. Social capital, networks, and knowledge transfer[J]. Academy of management review. 2005, 30(1): 146-165.

[5] Knowledge and social capital: Foundations and applications[M]. Routledge, 2000.

[6]Bundesministerium fuer Bildung und Forschung(BMBF).WiN- Wirtschaftswissenschaften für Nachhaltigkeit/economics for sustainability. 2010, Available at http://www.fona.de/de/9886.

[7] Andersen M M. Eco-innovation-towards a 